\title{
Technical and Medium-Term Clinical Outcomes of Transjugular Intrahepatic Portosystemic Shunt with Fluoroscopy and Additional Trans- abdominal Ultrasound Guidance
}

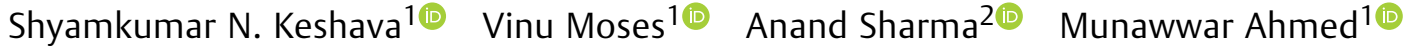

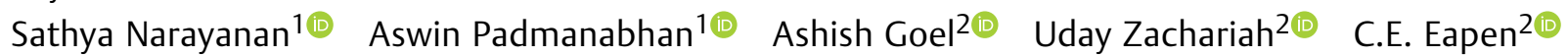 \\ ${ }^{1}$ Department of Interventional Radiology, Christian Medical College, \\ Address for correspondence Shyamkumar Nidugala Keshava, MBBS, \\ DMRD, DipNB, FRCR (UK), FRANZCR (Australia), Division of Clinical \\ Vellore, Tamil Nadu, India \\ 2 Department of Hepatology, Christian Medical College, Vellore, Tamil \\ Radiology, Department of Interventional Radiology, Christian Medical \\ Nadu, India \\ College Hospital, Vellore 632004, Tamil Nadu, India \\ (e-mail: shyamkumar.n.keshava@gmail.com).
}

Indian | Radiol Imaging 2021;31:858-866.

\begin{abstract}
Keywords

- transjugular intrahepatic portosystemic shunt

- fluoroscopic

- ultrasound

Background and Objective The aim of the study is to evaluate the technical and clinical outcomes of transjugular intrahepatic portosystemic shunt (TIPS) performed with additional transabdominal ultrasound guidance.

Material and Methods Patients who underwent TIPS between January 2004 to January 2020 in our center were studied. Technical, hemodynamic, angiographic, and clinical outcome were recorded up to 1 year of follow-up.

Results TIPS was attempted in 162 patients (median [range] age 37[3-69] years; 105 were males and 57 were females; Etiology: Budd-Chiari syndrome [BCS] 91, cirrhosis 65, symptomatic acute portal venous thrombosis [PVT] 3, veno-occlusive disease [VOD] 2, congenital portosystemic shunt [CPSS] 1) during the study period. Indication for TIPS was refractory ascites in 135 patients (BCS 86, cirrhosis 49) and variceal bleed in 21 patients (BCS 5, cirrhosis 16). Technical success was seen in 161 of the 162 (99.4\%) patients. The tract was created from hepatic vein in 55 patients and inferior vena cava (IVC) in 106 patients. Complications within 1 week post TIPS were seen in 29 of the 162 (18\%) patients, of whom one developed unexplained arrhythmia and hypotension and died. Of the patients with available follow-up, clinical success was noted in 120 (81\%), while $14(9 \%)$ patients had partial nonresponse and six (4\%) had complete nonresponse. Eight (5\%) patients died during the follow-up period.

Conclusion The technical success of TIPS creation with additional transabdominal ultrasound guidance is very high with low peri-procedural complication rate. It has enabled the inclusion of a wider spectrum of cases like acute PVT and obliterated hepatic veins which were otherwise considered contraindications.
\end{abstract}

published online November 30, 2021
DOI https://doi.org/ $10.1055 / \mathrm{s}-0041-1735928$ ISSN 0971-3026.

\footnotetext{
(C) 2021. Indian Radiological Association. All rights reserved.

This is an open access article published by Thieme under the terms of the Creative Commons Attribution-NonDerivative-NonCommercial-License, permitting copying and reproduction so long as the original work is given appropriate credit. Contents may not be used for commercial purposes, or adapted, remixed, transformed or built upon. (https://creativecommons.org/ licenses/by-nc-nd/4.0/)

Thieme Medical and Scientific Publishers Pvt. Ltd., A-12, 2nd Floor, Sector 2, Noida-201301 UP, India
} 


\section{Introduction}

Transjugular intrahepatic portosystemic shunt (TIPS) is considered a challenging interventional procedure. The key deciding factor is the creation of a liver parenchymal tract between the hepatic vein and the portal vein. Traditionally, the tract was created under fluoroscopic guidance. ${ }^{1}$ To improve the success rate, several techniques have been used, including indirect portography, wedge portography with iodinated contrast or $\mathrm{CO}_{2}$, transabdominal ultrasound (US) and computed tomography (CT) guidance. ${ }^{2}$ Since 2004 , we have been using transabdominal US guidance, in addition to fluoroscopy, while performing TIPS at our center. Direct intrahepatic cavo-portal shunts (DIPS) or a transcaval TIPS is a tract created between the inferior vena cava (IVC) to a branch of the portal vein. This is usually performed when a suitable hepatic vein is not available. Our initial case series on US-guided TIPS was published with technical details and immediate outcomes. ${ }^{3}$

\section{Methods}

\section{Data Collection}

Approval for this study was obtained from the Institutional Review Board (IRB: 1147 Retro dated: January 24, 2019). A retrospective study was conducted on patients on whom TIPS was attempted between January 2004 and January 2020 at our Department, which is located in a large tertiary care and teaching hospital in South India. The list of cases was obtained from PACS (Picture Archiving and Communication System). Clinical details were obtained from the patients' hospital records. Follow-up details were collected up to 1 year. Informed consent was obtained from patients prior to the standard of care established treatment.

\section{Patient Work-Up}

The patients referred for TIPS procedure underwent clinical and imaging evaluation. The latter primarily included US with Doppler. The liver size and presence of ascites were noted. Intrahepatic venous anatomy, especially the intrahepatic IVC, hepatic veins, and the portal vein, were assessed. The orientation of the veins was assessed from the possible tract options between the hepatic vein or IVC to a branch of the portal vein. If the information obtained from US and Doppler was found inadequate, additional contrast enhanced CT (CECT) examination was performed. Echocardiography was performed to exclude obvious cardiac insufficiency.

The bleeding parameters were checked and prothrombin (INR) corrected if $>1.5$. Platelet infusion was considered when the counts were below 50,000 per microliter. Since 2015, our center has been doing thromboelastography to estimate the risk of bleeding during the procedure. Correction of bleeding parameters was done as per advice from the Transfusion Medicine department of our Institution. For gross ascites, partial therapeutic drainage was performed before the procedure. All patients received prophylactic antibiotics before the procedure.
Refractory variceal bleed was defined as failure to control bleed with pharmacological and endoscopic therapy. ${ }^{4}$ Refractory ascites is defined as ascites that cannot be mobilized or the early recurrence of which cannot be satisfactorily prevented by medical therapy. ${ }^{5}$ Prior to doing TIPS, the Model for end-stage liver disease (MELD) score was calculated for all patients; similarly, the BCS-TIPS prognostic index was calculated for patients with Budd-Chiari syndrome (BCS). ${ }^{6,7}$

\section{Steps of TIPS}

The steps of the procedure are similar to what has been previously described from our center. ${ }^{3}$ A summary of the steps with comments is mentioned in - Table 1. The orientation of the equipment and the medical staff with respect to the patient is demonstrated in -Fig. $\mathbf{1}$.

If there was no contraindication, patients were started on heparin that was changed to an oral vitamin $\mathrm{K}$ antagonist after a period of overlap to maintain a prothrombin time international normalized ratio (INR) between 2 and 3 .

\section{Special Circumstances}

If there was a previously placed stent in the path of TIPS creation, strut plasty was performed and TIPS was created. ${ }^{8,9}$ Stents would have been placed to treat BCS in IVC or hepatic veins.

If the indication was acute portal venous thrombosis (PVT), then portal venous entry of the needle, while creating the tract, was monitored on US only. The details of TIPS procedure in patients with acute portal vein thrombosis have been previously described. ${ }^{10}$ After placement of the stent, suction thrombectomy and thrombolysis were performed to relieve the portal vein thrombus. If TIPS was performed during pregnancy, extreme care was taken to restrict the radiation, for inevitable indications.

In children, the same Rosch Uchida needle (RUPS) set was used. However, the size of the stent caliber used was smaller, depending upon the diameter of the main portal vein.

In case of congenital porto-system shunt (CPSS/Abernathy malformation), TIPS has a role in those patients who have large congenital shunts, and who are at a higher risk of developing acute portal hypertension following the closure of the shunt.

\section{Follow-Up Protocol}

Stent patency was assessed using US Doppler at the time of discharge, and at 3 months, 6 months, and 1 -year postprocedure, or if clinically indicated.

\section{Outcome of TIPS}

Assessment of the success of the procedure was based on four aspects-technical, hemodynamic, angiographic, and clinical. Technical success was defined as the creation of a shunt between the hepatic vein and the intrahepatic branch of the portal vein. ${ }^{11}$ Hemodynamic success was defined as a reduction in the pressure gradient across the shunt to below $12 \mathrm{~mm} \mathrm{Hg} .{ }^{12}$ Angiographic success was defined as more than $50 \%$ of the contrast flowing into the shunt during the 
Table 1 Steps of fluoroscopic and additional US guided TIPS and DIPS (trans-caval TIPS)

\begin{tabular}{|c|c|c|}
\hline Step of the procedure & Details & Comments "dos and don'ts" \\
\hline Location & $\begin{array}{l}\text { Siemens Multistar or Artis Zee Siemens } \\
\text { Healthcare AG, Forchheim, Germany }\end{array}$ & Any DSA suite should do \\
\hline Patient positioning & Supine, head turned toward left & $\begin{array}{l}\text { If through left IJV, turn the head toward } \\
\text { right side }\end{array}$ \\
\hline Anesthesia & General & Conscious sedation is the alternative \\
\hline Jugular access & 5F sheath & $\begin{array}{l}\text { Right side, under US guidance } \\
\text { If unsuitable, left side }\end{array}$ \\
\hline Cannulation of RHV & 5F multipurpose catheter, $0.035 "$ glide wire & $\begin{array}{l}\text { Cross check the position within RHV by } \\
\text { trans-abdominal US (Orientation } \\
\text { in - Fig. 1) }\end{array}$ \\
\hline $\begin{array}{l}\text { Hepatic venogram, pressure } \\
\text { measurements }\end{array}$ & $5 \mathrm{~F}$ multipurpose catheter & $\begin{array}{l}\text { Pressures from RA, RHV, and HVPG } \\
\text { (when possible) }\end{array}$ \\
\hline Cannula placement in RHV & $\begin{array}{l}\text { RUPS } 100 \text { set } \\
\text { Tip of the cannula placed in the RHV (TIPS) or } \\
\text { just below the HV confluence in the IVC (DIPS) }\end{array}$ & $\begin{array}{l}\text { Gentle curve in the distal portion of the } \\
45-\mathrm{cm} \text { long } 7-\mathrm{Fr} \text { cannula if needed, } \\
\text { more curve for DIPS. }\end{array}$ \\
\hline Tract creation & $\begin{array}{l}\text { Aim the RPV between the PV confluence and } \\
\text { the first division. } \\
\text { Alternate fluroscopic and US guidance. } \\
\text { US guidance to adjust the appropriate angle } \\
\text { of the access needle for PV puncture. } \\
\text { Real-time US guidance in anterolateral } \\
\text { oblique sagittal plane. } \\
\text { Enter the RPV with a gentle jab. }\end{array}$ & $\begin{array}{l}\text { "a single wall, single puncture" } \\
\text { Avoid extrahepatic puncture } \\
\text { Prevent any air to get into the system; } \\
\text { dribble saline whenever metal needle is } \\
\text { withdrawn. } \\
\text { Look for blood from the hub of plastic } \\
\text { cannula. }\end{array}$ \\
\hline Cannulation of the portal system & $\begin{array}{l}0.035 " \text { stiff glide wire } \\
\text { (Terumo Corporation, Tokyo, Japan) }\end{array}$ & $\begin{array}{l}\text { Manipulate under fluroscopy in such a } \\
\text { way that the wire turns medially, place } \\
\text { well inside SMV or SV. } \\
\text { US is the alternative guidance, } \\
\text { especially if there is PV thrombosis. }\end{array}$ \\
\hline $\begin{array}{l}\text { Portogram and IVCgram and } \\
\text { pressure measurement }\end{array}$ & Marker pigtail & $\begin{array}{l}\text { Study the morphology of the portal } \\
\text { system, size of the PV, site of entry into } \\
\text { the PV, large varices. } \\
\text { PV pressure }\end{array}$ \\
\hline Plasty of the tract & $8 \mathrm{~mm}$ or $10 \mathrm{~mm}$ balloon, $4 \mathrm{~cm}$ length & $\begin{array}{l}\text { If likely chance of developing hepatic } \\
\text { encephalopathy, } 8 \mathrm{~mm} \text { diameter was } \\
\text { used. } \\
\text { If balloon cannot be advanced, use } \\
\text { smaller balloons for the initial } \\
\text { dilatation. }\end{array}$ \\
\hline Stent placement & $\begin{array}{l}\text { Viatorr stent-graft (Gore, Flagstaff, Arizona, } \\
\text { United States) } \\
\text { Niti-S (Taewoong Medical, Seoul, South } \\
\text { Korea) } 10 \mathrm{~mm} \text { diameter }\end{array}$ & $\begin{array}{l}\text { Adequacy of the stent-to cover the } \\
\text { entire parenchymal tract, uncovered } \\
\text { stent well in the main portal vein, } \\
\text { upper end well in IVC. } \\
\text { Post plasty if the stent expansion is } \\
\text { inadequate. } \\
\text { Assess the shape of the tract A wide "C" } \\
\text { is desirable, other shapes are "L" and } \\
\text { "V." }\end{array}$ \\
\hline Portogram and pressure gradient & Less than $12 \mathrm{~mm} \mathrm{Hg}$ is favorable & $\begin{array}{l}\text { Any varices attributable to the clinical } \\
\text { presentation may be embolized if the } \\
\text { pressure gradient is high or grossly } \\
\text { filling. }\end{array}$ \\
\hline Extubation & Manuel compression of the access site & Monitoring in ICU for $24 \mathrm{~h}$. \\
\hline
\end{tabular}

Abbreviations: DIPS, direct intrahepatic porto-systemic shunt; DSA, digital subtraction angiography; HVPG, hepatic vein pressure gradient; IJV, internal jugular vein; IVC, inferior vena cava; PV, portal vein; RA, right atrium; RHV, right hepatic vein; RUPS 100, Rösch-Uchida Transjugular Liver Access Set (Cook, Bloomington, IN); SMV, superior mesenteric vein; SV, splenic vein; US, ultrasound. 


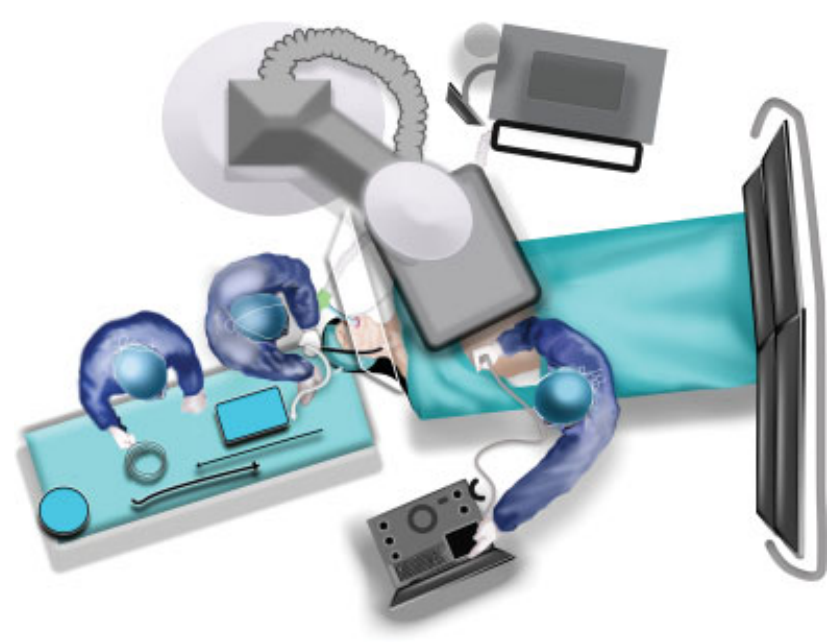

Fig. 1 Schematic diagram, view from above shows main operator stands on the head end of the patient and performs the procedure and another operator performs per abdomen ultrasonography to shows relation of cannula-needle position and direction toward target portal vein branch.

post-procedure portography, along with a reduction in the flow to the pre-existing varices. Clinical success was defined as a resolution of the clinical problem for which the procedure was indicated. ${ }^{11}$ Clinical non-response to TIPS in patients with ascites was considered partial, if ascites persisted, but there was a reduction in frequency of therapeutic paracentesis or dose of diuretics; further, it was considered complete if there was no change in the frequency of therapeutic paracentesis and diuretic dose. Clinical non-response to TIPS in patients with portal hypertensive bleed was considered complete if the patient had recurrent portal hypertensive bleed, and partial, if the patient continued to have large gastroesophageal varices in the absence of recurrent portal hypertensive bleed. Adverse events were recorded during the procedure and the immediate post procedure period. Follow-up was recorded up to 1 year and adverse events were subcategorized into $<7$ days, from 7 days to a month and a month to a year after the TIPS procedure. Adverse events were classified as major or minor according to the Society of Interventional Radiology classification system. ${ }^{13}$

\section{Adequacy of the Shunt}

We assessed the extent of the stent coverage on either side of the puncture. The site of puncture should ideally be within $2 \mathrm{~cm}$ of the portal venous confluence, and it should not involve the extrahepatic segment of portal branches. The covered portion of the stent should adequately cover the liver parenchyma. The desirable shape of the final shunt is a wide "C" in AP view.

\section{Statistical Analysis}

Continuous variables were expressed as median and range and categorical variables were expressed as number and percentages. The analysis was done using Microsoft Excel 2016.

\section{Results}

\section{Demographics}

There were 162 patients (105 males and 57 females), with the median age (range) being 37 (3-69) years. The etiology underlying the indication for TIPS/DIPS was BCS in 91 (56\%) patients, cirrhosis with portal hypertension in 65 (40\%) patients, symptomatic acute PVT in three (2\%) patients, veno-occlusive disease (VOD) in two (1\%) patients, and congenital portosystemic shunt in one (1\%) patient. Among the patients with cirrhosis with portal hypertension, refractory variceal bleed was the indication in 16 of the 65 cases (25\%) and refractory ascites in 49 of the 65 cases (75\%). One patient had a duodenal varix, which was embolized in the same session as the TIPS procedure. The median MELD score was 11 (6-27) in these 65 patients. Among the BCS patients, 86 of the 91 cases (95\%) had refractory ascites, while five (5\%) had variceal bleeding. In patients with BCS, the median BCS TIPS prognostic index was 3.7 (1.1-6.5) and the median MELD score was 12 (6-25). The indication for TIPS in patients with VOD was refractory ascites; the patient with CPSS was asymptomatic but underwent prophylactic TIPS prior to the closure of the shunt. One patient, who was pregnant with 29 weeks gestation at the time of the procedure, underwent emergency TIPS for BCS-related variceal bleed, which was refractory to endoscopic therapy.

\section{Technical Details of TIPS Intervention}

The procedure was performed through the right IJV in 160 of the 162 patients and through the left IJV in the remaining two patients. Technical success was achieved in all but one patient -this patient had cirrhosis with PVT. In this particular patient, attempts at TIPS were unsuccessful and the visibility was poor due to the entry of air from the cannula into the region of shunt creation.

The tract was created from the IVC in 106 (DIPS) and the hepatic vein in 55 (conventional TIPS) patients. The portal entry was into the right branch in 127 and left in 33 of the total 161 patients. One entry of the 161 cases was to the fistulous communication of the CPSS. The tract length varied between $1 \mathrm{~cm}$ and $10 \mathrm{~cm}$. The tracts were longer in DIPS than TIPS, with lengths of $6(1-10) \mathrm{cm}$ and $4(2-8) \mathrm{cm}$, respectively. The diameter of the balloon catheter was predominantly 10 and $8 \mathrm{~mm}$ that was used in 85 and 73 patients, respectively. Smaller balloons, measuring $6 \mathrm{~mm}$, were used in three cases -children or patients with a small build. The stents used included Viatorr stent-graft (Gore, Flagstaff, Arizona, United States) $(n=63)$ and Niti-S (Taewoong Medical, Seoul, South Korea) $(n=72)$. A combination of uncovered-covered stents and uncovered self-expandable stents alone was placed in 14 and 11 patients, respectively. The reason for using different stents was mainly due to the availability of the stents at that point in time. The average length of the covered portion of the stent was $7.3 \mathrm{~cm}$.

Of the 106 patients in whom the tract was created from the IVC, IVC plasty had to be done prior to the TIPS during the same sitting in three patients, all of whom had BCS. Strut plasty was done in seven patients, specifically in five through 
the previously placed IVC stent and in two via the right hepatic vein (RHV) stents.

\section{Procedure Outcome-Technical, Hemodynamic, and Angiographic Success}

Technical success was achieved in 161 of the 162 (99.4\%) patients. Pressure gradient data was available for 139 patients, in whom hemodynamic success (reduction of pressure gradient to less than $12 \mathrm{~mm} \mathrm{Hg}$ ) was achieved in 132 (95\%) patients. In the remaining seven (5\%) patients, there was a reduction in pressure gradient, but it remained in the range of 13 to $18 \mathrm{~mm} \mathrm{Hg}$. Angiographic success was achieved in 156 of the $161(97 \%)$ patients.

In all the patients, there was an adequate extension of the stents to the portal and systemic sides. All the stents expanded to the desired caliber. The site of entry to the portal vein was within $2 \mathrm{~cm}$ in 130 (82.8\%) and 2 to $4 \mathrm{Am}$ in 27 (17.1\%) of the 157 patients, respectively. In three patients who had acute PVT, the portal puncture was close to the confluence as per US. In one patient who had CPSS, the shunt close to the PV was punctured. There was no direct puncture of the main PV.

\section{Clinical Outcomes in Immediate and Midterm Follow-Up}

Of the 161 patients in whom TIPS was created successfully, 14 patients had undergone TIPS within 1 year of this study (May 2019 to April 2020). Follow-up data was available for 149 patients. Seven patients were lost to follow-up and five patients underwent TIPS within 3 months of writing this article and, hence, their clinical responses have not yet been assessed. Clinical success was noted in 120 out of the 149 (81\%) patients, whereas 20 patients showed partial or complete non-response, and eight patients died during the follow-up period. In one patient, who had a large CPSS, TIPS was performed prior to the closure of the congenital shunt and we did not expect any clinical change. Among the 20 patients who did not show clinical response following TIPS, the underlying etiology was cirrhosis in 16 patients, BCS in three and VOD in one patient. Fourteen out of these 20 patients showed partial non-response in the form of reduction in the frequency of paracentesis and diuretic dose, while six out of 20 patients did not have any clinical response despite a patent stent. One patient with complete nonresponse underwent liver transplantation during the follow-up period.

\section{Adverse Events in the Immediate and Midterm Follow-Up}

Adverse events have been detailed in - Table 2. Of the 162 patients in whom TIPS was attempted, 49 (30\%) patients developed major AE during the follow-up period, with 29 (18\%) of these occurring within a week of the procedure. Hepatic encephalopathy (HE) was the most common AE noted in 16 (10\%) patients and occurred in seven of these patients in the first week following TIPS. They were all managed successfully with standard medical measures. Reduction in stent diameter was not done in any patient. Sepsis was the next most common $\mathrm{AE}$ and occurred in 11 (7\%) patients. They were managed with antibiotics. One patient, who was pregnant during the procedure, suffered a miscarriage 67 days after TIPS.

Six patients, all of whom underwent TIPS for the indication of refractory ascites, developed incarcerated umbilical hernia during the follow-up period. The underlying etiology of refractory ascites was BCS in cirrhosis in four patients and BCS in two patients. Of these six patients, four patients were managed surgically and the remaining two conservatively with successful reduction of hernia. One patient, who underwent surgery, showed improvement in the early postoperative period, but developed spontaneous bacterial peritonitis (SBP) 10 days after surgery and died.

\section{Mortality during Follow-Up}

During the follow-up period, eight patients died 25 (2-246) days after the TIPS procedure. The cause of death was infection in four patients (lower respiratory tract infection 2, SBP 2), HE followed by aspiration pneumonia in two patients, recurrent $\mathrm{HE}$ in a patient and another patient developed unexplained cardiogenic shock immediately after the procedure and died. Of these eight patients, one patient underwent re-intervention for stent occlusion during the follow-up period.

\section{Occlusion of TIPS Stents during the Follow-Up Period} Occlusion of the stents was noted in 12 patients within 1 month of TIPS and in 16 patients between 1 month and 1 year of TIPS. Of the 12 stents placed, three were Viatorr stent-graft (Gore, Flagstaff, Arizona, United States), seven were Niti-S (Taewoong Medical, Seoul, South Korea), and two were bare metal stents. Of the 12 patients who developed occlusion of stent within 1 month of TIPS, the occlusion was tackled successfully in 10 patients with angioplasty of the stent. The details of this aspect will be presented in a forthcoming article.

\section{Discussion}

In this study, the predominant indication for TIPS was ascites caused by BCS. This could be explained by the referral bias to our tertiary care center and institutional practice.

\section{The Pre-procedure Imaging Work-Up}

We managed most of our procedures with preprocedure US and Doppler evaluations. The purpose of this was to evaluate the hepatic veins, portal vein, and their anatomical relations. With respect to portal venous anatomy, one needs to evaluate the size, branching pattern, and any evidence of acute or chronic thrombosis. It is also important to identify if the portal venous bifurcation is intrahepatic or extrahepatic. In the case of BCS, patency of the inferior vena cava (IVC) has to be assessed. Contrast-enhanced CT (CECT) was done when there had been previous interventions like endovascular treatment for BCS. In such situations, CT would help in determining the condition of the previously placed stent. We also performed CECT when there was a suspicion of an 
Table 2 Adverse events in the 162 patients in whom transjugular intrahepatic portosystemic shunt (TIPS) was attempted

\begin{tabular}{|c|c|c|c|c|}
\hline $\begin{array}{l}\text { Time from } \\
\text { TIPS procedure }\end{array}$ & Major adverse events & $\begin{array}{l}\text { Number } \\
\text { of patients }\end{array}$ & Minor adverse events & $\begin{array}{l}\text { Number } \\
\text { of patients }\end{array}$ \\
\hline \multirow[t]{16}{*}{$<7 d$} & $\begin{array}{l}\text { Procedure related adverse events } \\
\text { (Technique related) }\end{array}$ & & \multirow[t]{2}{*}{$\begin{array}{l}\text { Procedure related adverse events } \\
\text { (Technique related) }\end{array}$} & \\
\hline & Hemobilia & $1(0)$ & & \\
\hline & \multirow{2}{*}{$\begin{array}{l}\text { Unexplained cardiac arrhythmia } \\
\text { and hypotension }\end{array}$} & \multirow[t]{2}{*}{$1(1)$} & Puncture site bleed & $2(0)$ \\
\hline & & & \multirow{13}{*}{$\begin{array}{l}\text { Breaking of tip of black plastic } \\
\text { sheath covering the 14-gage } \\
\text { covering stiffening cannula of RUPS } \\
\text { (left within liver parenchyma). }\end{array}$} & \multirow{13}{*}{$1(0)$} \\
\hline & $\begin{array}{l}\text { Procedure related adverse events } \\
\text { (Technique unrelated) }\end{array}$ & & & \\
\hline & Difficult extubation & $4(0)$ & & \\
\hline & Post procedure self-limiting fever & $1(0)$ & & \\
\hline & Post procedure hepatitis & $1(0)$ & & \\
\hline & Hemoptysis & $1(0)$ & & \\
\hline & \multicolumn{2}{|l|}{ Medical adverse events } & & \\
\hline & Acute kidney injury & $3(0)$ & & \\
\hline & $\begin{array}{l}\text { Pulmonary hypertension and } \\
\text { cardiac failure }\end{array}$ & $1(0)$ & & \\
\hline & Lower respiratory infection & $1(1)$ & & \\
\hline & Hepatic encephalopathy & $7(0)$ & & \\
\hline & Bacteremia & $4(0)$ & & \\
\hline & Spontaneous bacterial peritonitis & $4(1)$ & & \\
\hline $7 \mathrm{~d}$ to $1 \mathrm{mo}$ & $\begin{array}{l}\text { Hepatic encephalopathy } \\
\text { Spontaneous bacterial peritonitis }\end{array}$ & $\begin{array}{l}7(2) \\
1(1)\end{array}$ & & \\
\hline \multirow[t]{3}{*}{$1 \mathrm{mo}$ to $1 \mathrm{y}$} & $\begin{array}{l}\text { Pulmonary hypertension and } \\
\text { cardiac failure }\end{array}$ & $2(0)$ & & \\
\hline & Hepatic encephalopathy & $2(1)$ & & \\
\hline & Lower respiratory infection & $1(1)$ & & \\
\hline \multicolumn{5}{|c|}{ Surgical adverse events } \\
\hline$<1 \mathrm{mo}$ & Obstructed umbilical hernia & $4(0)$ & & \\
\hline $1 \mathrm{mo}$ to $1 \mathrm{y}$ & Obstructed umbilical hernia & $2(0)$ & & \\
\hline \multicolumn{5}{|c|}{ Adverse events probably unrelated to TIPS procedure } \\
\hline \multicolumn{2}{|c|}{ Intrauterine death } & $1(0)$ & & \\
\hline \multicolumn{5}{|l|}{ Stent occlusion } \\
\hline \multicolumn{2}{|c|}{$<1$ mo post procedure } & 12 & & \\
\hline \multicolumn{2}{|c|}{$1 \mathrm{mo}$ to 1 y post procedure } & 16 & & \\
\hline
\end{tabular}

Note: Number in parentheses denotes patient who died of the respective complications.

acquired abnormality of the portal vein, like acute or chronic thrombosis.

\section{Additional Image Guidance during TIPS}

Usually, there are several attempts made during the conventional TIPS procedure. Minimizing the number of attempts, while creating the TIPS tract, has many advantages. These include a higher success rate, a lower rate of complication, a reduced duration of procedure, and lower radiation exposure. The main advantage of additional transabdominal US is that it makes it possible to visualize the tract being created in real-time. Further, there are the additional advantages of the universal availability, adequate resolution, and low cost of the US.

A good orientation to the specific anatomy is essential even before the patient is taken up for the procedure. The US is useful in detecting (a) the location of the cannula tip, (b) tracking of the needle in the liver parenchyma, and (c) entry of the needle into the portal vein. In case of conventional TIPS, the US helps in confirming the selected vein as the RHV and its location behind the right branch of the PV (RPV). Sometimes, the middle hepatic vein (MHV) can be mistaken for the RHV on fluoroscopy in the presence of ascites and variation in the volume of liver parenchyma. The 
visualization of the cannula tip is of greater importance in case of DIPS to avoid inadvertent suprahepatic IVC puncture. In addition, the site of the portal venous entry can also be more precisely decided. As US is a dynamic imaging technique, the movement of the liver during each phase of respiration is inconsequential. It also provides superior visualization of the anteroposterior orientation of the hepatic veins (HV) or IVC to the portal vein. This helps in altering the cannula curve, if required. DIPS may be considered even when the HVs are patent, but do not have favorable anatomical relation to the PV. Further, it brings down the requirement of iodinated contrast, as fewer angiographic runs are done. There is no need to perform $\mathrm{CO}_{2}$ angiography. Some of the complications mentioned in the literature are related to $\mathrm{CO}_{2}$ angiography. ${ }^{14}$

In case of BCS, hepatic veins are obliterated and wedge portography is not possible. With the help of US, it is possible to create a longer tract, especially from the IVC, instead of the hepatic vein. The real-time visualization also helps in preventing overshooting of the portal branch or transcapsular puncture. There is no need to drain the ascites or completely correct the bleeding parameters if the procedure is done under US guidance. US facilitates a reduction in the time taken to create the tract and, thus, in the overall duration of the procedure. The radiation dose is also approximately reduced to one-third. ${ }^{15}$ US is also potentially useful in detecting new onset PVT. Isolated portal vein thrombosis may be asymptomatic till it extends to the splanchnic veins.

Increased exposure to radiation is a concern in technically challenging circumstances like BCS and PVT, as well as in vulnerable populations like children and pregnant women. US guidance has an additional advantage in that it reduces the dose of radiation. ${ }^{15}$

All precautions need to be taken to prevent air-entry at the site of tract creation. This may be achieved by generous saline dripping at the hub of the plastic cannula, while removing the metal needle to pass the glide wire. Otherwise, the air sucked into the plastic cannula has a tendency to be displaced to the hepatic parenchyma at the time of reinsertion of the needle. Also, any flushing of the cannula, if required, should be done in a wedged position. If air enters, it can obscure further visualization with US.

Intravascular ultrasound (IVUS) provides excellent guidance to create the shunt. ${ }^{16,17}$ The IVUS probe is placed from the transfemoral access and TIPS is performed from the jugular access. The tract may be performed through the caudate lobe of the liver. The closer view also helps in avoiding puncture of the biliary radicles and hepatic arteries. However, availability and additional cost are issues to be considered. $C T$ has been used to create a TIPS tract transvenously as well as percutaneously. ${ }^{18,19}$ There are also reports suggesting the use of magnetic resonance imaging (MRI) for additional image guidance. ${ }^{20}$

\section{Comparison of the Outcome-Success and Complications}

The success in TIPS ranges from 67 to $100 \%$ in 19 case series. $^{21}$

Most studies refer to technical success as the success of the procedure. However, the success of the procedure can be better assessed by evaluating technical, angiographic, hemodynamic, and clinical aspects. Fanelli et al in a recent study achieved technical success in 100\% patients and hemodynamic success (pressure gradient $<12 \mathrm{~mm} \mathrm{Hg}$ ) in $90.1 \%$ patients. In various studies, TIPS related death rates range from 3 to $5 \% .^{21-24}$ In our study, procedure-related mortality was one out of 162 patients $(0.4 \%$.) The major complications described in literature include hemoperitoneum, stent malpositioning, haemobilia, hepatic infarction, and resistant hepatic encephalopathy. The minor complications described include biliary duct puncture, gallbladder puncture, right kidney puncture, transient pulmonary edema, transient hepatic encephalopathy, and transient renal failure. Such complications may occur in 4 to $8 \%$ of the cases. ${ }^{21,22}$ All the abovementioned and other complications occur due to (1) nontarget puncture, (2) reduced perfusion of the liver, (3) contrast-related issues (4) infections and, (5) device-(catheter, stent, etc.) related issues. Hepatic ischemia can result either by the covered stent encroaching the HV/PV or compression of the hepatic artery following stent placement. Contrast-related complications are common, as some of these patients have deranged renal function or may have received large amounts of contrast. Patients with cirrhosis are predisposed to renal injury due to splanchnic vasodilation and reduced renal perfusion. ${ }^{25}$ It is possible that the longer duration of the procedure increases the chances of infection. Chances of malpositioning of the stent may be reduced by creating a wide $C$-shaped tract, which mainly depends on the site of puncturing the PV. US-guided punctures contribute to reduce the probability of most of the above complications, as evident in the current study.

During the post-procedural period, the most common medical complication in our patients was HE, that occurred in 16 (9.8\%) patients, with seven occurring in the immediate ( $<7$ days) post-procedure period. However, these patients were all managed successfully with medical measures. Deaths in patients with HE (3/16) were uncommon in our patients during the study period. Post TIPS HE has been reported in 34 to $42 \%$ patients in literature. ${ }^{26}$ The relatively low rates of post TIPS HE in our study may be due to the fact that a majority of our patients had underlying BCS and better synthetic function of the liver than patients with decompensated cirrhosis who formed the majority in the abovementioned studies. A majority of the HE that occurred were noted in the early part of the post TIPS period. This may be because the diameter of the TIPS stent decreases spontaneously with time as does the portosystemic shunting, resulting in a decreased propensity of HE later on in the patient. ${ }^{27}$ In patients who were likely to develop $\mathrm{HE}$, plasty was done with an $8-\mathrm{mm}$ balloon instead of a $10-\mathrm{mm}$ balloon and the placement of $10-\mathrm{mm}$ stents, so that the tract expansion was gradual. We had the option of dilating the stent to $10 \mathrm{~mm}$ when needed. Sepsis was the next most common complication, occurring in 11 patients in our study (bacteremia, 4, SBP, 5 , and lower respiratory infection, 2). Further, most cases occurred within a month following TIPS. The patients developing bacteremia (four patients) were those with underlying 
decompensated cirrhosis. This observation has been seen in other studies as well. ${ }^{28}$ Other TIPS-related adverse events like acute kidney injury and pulmonary hypertension occurred less commonly and was managed successfully.

Obstructed umbilical hernia was noted in six out of 161 patients. This complication has been described after TIPS for refractory ascites in $6 \%$ of the patients. ${ }^{29}$ It has been suggested that a rapid reduction in ascites after TIPS causes a decrease in the size of umbilical defect, thereby predisposing the patient to incarceration of the hernial contents. ${ }^{30} \mathrm{We}$ suggest that umbilical hernia should be manually reduced prior to mobilizing a large volume of ascites and should be monitored post TIPS.

\section{Widened Spectrum of Indications for TIPS}

Some of the listed relative contraindications in AASLD guidelines are no more contraindications for TIPS; instead, they have turned out to be indications. ${ }^{31}$ In a subsequent update, BCS has been included as an indication. ${ }^{32}$ In our series, the commonest etiology was BCS. Acute portal vein thrombosis has emerged as a new indication, where TIPS is useful in recanalization and, thus, reduces the chance of future portal cavernoma. ${ }^{33,34}$ Based on these findings, the guidelines for TIPS need to be suitably revisited. ${ }^{35}$

The limitation of the study is its retrospective nature. We do not have recordings of the number of attempts to create the tract and the duration of the procedure. The radiation dose was not recorded from all patients; however, a small group of patients from the current cohort showed significantly low radiation exposure. ${ }^{15}$

\section{Conclusion}

Transabdominal US has significant advantages when used as an additional image guiding tool during TIPS procedure, resulting in an increase in the success rates of the procedure and lower rates of complications. Universal availability and real-time guidance makes transabdominal US an attractive tool as compared with IVUS. US guidance will benefit more patients, as it widens the spectrum of indications, including certain conditions like acute PVT, and obliterated hepatic veins, which were otherwise considered as contraindications. As additional US guidance increases success rates to almost $100 \%$, it decreases peri-procedural complications, reduces radiation doses, and broadens the spectrum of indications for TIPS, we recommend that it be used routinely for all TIPS procedures.

\section{Ethical Approval \\ Obtained.}

\author{
Funding \\ None. \\ Conflict of Interest \\ None declared.
}

\section{Acknowledgments}

We thank Dr. Balasubramaniam Karthikumar for drawing - Fig. 1 and Dr. Pippa Pavamani for the manuscript corrections.

\section{References}

1 Richter GM, Palmaz JC, Nöldge G, et al. The transjugular intrahepatic portosystemic stent-shunt. A new nonsurgical percutaneous method. Radiologe 1989;29(08):406-411

2 Farsad K, Kaufman JA. Novel image guidance techniques for portal vein targeting during transjugular intrahepatic portosystemic shunt creation. Tech Vasc Interv Radiol 2016;19(01):10-20

3 Keshava SN, Kota GK, Mammen T, et al. Direct intrahepatic cavoportal shunts in Budd-Chiari syndrome: role of simultaneous fluoroscopy and trans-abdominal ultrasonography. Indian J Gastroenterol 2006;25(05):248-250

4 Escorsell À, Pavel O, Cárdenas A, et al; Variceal Bleeding Study Group. Esophageal balloon tamponade versus esophageal stent in controlling acute refractory variceal bleeding: a multicenter randomized, controlled trial. Hepatology 2016;63(06): 1957-1967

5 European Association for the Study of the Liver. Electronic address: easloffice@easloffice.eu European Association for the Study of the Liver. EASL clinical practice guidelines for the management of patients with decompensated cirrhosis. J Hepatol 2018;69(02):406-460

6 Asrani SK, Kim WR. Model for end-stage liver disease: end of the first decade. Clin Liver Dis 2011;15(04):685-698

7 Garcia-Pagán JC, Heydtmann M, Raffa S, et al; Budd-Chiari Syndrome-Transjugular Intrahepatic Portosystemic Shunt Group. TIPS for Budd-Chiari syndrome: long-term results and prognostics factors in 124 patients. Gastroenterology 2008;135(03): $808-815$

8 Surendrababu NR, Keshava SN, Eapen CE, Zachariah UG. Transjugular intrahepatic portocaval shunt placed through the strut of an inferior vena cava stent in a patient with Budd-Chiari syndrome: a technical modification. Br J Radiol 2010;83(985): e22-e24

9 Ahmed M, Keshava SN, Moses V, et al. Transjugular intrahepatic portosystemic shunt through the strut of a previously placed stent: technical feasibility and long-term follow-up results. Cardiovasc Intervent Radiol 2018;41(11):1794-1798

10 Mammen S, Keshava SN, Kattiparambil S. Acute portal vein thrombosis, no longer a contraindication for transjugular intrahepatic porto-systemic shunt (TIPS) insertion. J Clin Exp Hepatol 2015;5(03):259-261

11 Fanelli F. The evolution of transjugular intrahepatic portosystemic shunt: tips. ISRN Hepatol 2014;2014:762096

12 Rössle M, Siegerstetter V, Olschewski M, Ochs A, Berger E, Haag K. How much reduction in portal pressure is necessary to prevent variceal rebleeding? A longitudinal study in 225 patients with transjugular intrahepatic portosystemic shunts. Am J Gastroenterol 2001;96(12):3379-3383

13 Beathard GA, Urbanes A, Litchfield T. The classification of procedure-related complications-a fresh approach. Semin Dial 2006; 19(06):527-534

14 Semba CP, Saperstein L, Nyman U, Dake MD. Hepatic laceration from wedged venography performed before transjugular intrahepatic portosystemic shunt placement. J Vasc Interv Radiol 1996;7(01):143-146

15 Livingstone RS, Keshava SN. Technical note: reduction of radiation dose using ultrasound guidance during transjugular intrahepatic portosystemic shunt procedure. Indian J Radiol Imaging 2011;21 $(01): 13-14$ 
16 Farsad K, Fuss C, Kolbeck KJ, et al. Transjugular intrahepatic portosystemic shunt creation using intravascular ultrasound guidance. J Vasc Interv Radiol 2012;23(12):1594-1602

17 Hodgson JM, Graham SP, Savakus AD, et al. Clinical percutaneous imaging of coronary anatomy using an over-the-wire ultrasound catheter system. Int J Card Imaging 1989;4(2-4):187-193

18 Zabicki B, Ricke J, Dudeck O, Pech M. CT-assisted transfemoral intrahepatic portosystemic shunt in a long duration follow-up: a case report. Pol J Radiol 2014;79:39-41

19 Quinn SF, Sheley RC, Semonsen KG. Creation of a portal vein to inferior vena cava shunt using CT guidance and a covered endovascular stent. AJR Am J Roentgenol 1997;169(04):1159-1160

20 Kee ST, Ganguly A, Daniel BL, et al. MR-guided transjugular intrahepatic portosystemic shunt creation with use of a hybrid radiography/MR system. J Vasc Interv Radiol 2005;16(2 Pt 1):227-234

21 Qi X, Han G. Transjugular intrahepatic portosystemic shunt in the treatment of portal vein thrombosis: a critical review of literature. Hepatol Int 2012;6(03):576-590

22 Fidelman N, Kwan SW, LaBerge JM, Gordon RL, Ring EJ, Kerlan RK Jr. The transjugular intrahepatic portosystemic shunt: an update. AJR Am J Roentgenol 2012;199(04):746-755

23 Deibert P, Schwarz S, Olschewski M, Siegerstetter V, Blum HE, Rössle M. Risk factors and prevention of early infection after implantation or revision of transjugular intrahepatic portosystemic shunts: results of a randomized study. Dig Dis Sci 1998;43 (08):1708-1713

24 Cura M, Cura A, Suri R, El-Merhi F, Lopera J, Kroma G. Causes of TIPS dysfunction. AJR Am J Roentgenol 2008;191(06):1751-1757

25 Garcia-Tsao G, Parikh CR, Viola A. Acute kidney injury in cirrhosis. Hepatology 2008;48(06):2064-2077

26 Zheng M, Chen Y, Bai J, et al. Transjugular intrahepatic portosystemic shunt versus endoscopic therapy in the secondary prophy- laxis of variceal rebleeding in cirrhotic patients: meta-analysis update. J Clin Gastroenterol 2008;42(05):507-516

27 Popovic P, Stabuc B, Skok P, Surlan M. Transjugular intrahepatic portosystemic shunt versus endoscopic sclerotherapy in the elective treatment of recurrent variceal bleeding. J Int Med Res 2010;38(03):1121-1133

28 Pleguezuelo M, Benitez JM, Jurado J, Montero JL, De la Mata M. Diagnosis and management of bacterial infections in decompensated cirrhosis. World J Hepatol 2013;5(01):16-25

29 Smith MT, Rase B, Woods A, et al. Risk of hernia incarceration following transjugular intrahepatic portosystemic shunt placement. J Vasc Interv Radiol 2014;25(01):58-62

30 Trotter JF, Suhocki PV. Incarceration of umbilical hernia following transjugular intrahepatic portosystemic shunt for the treatment of ascites. Liver Transpl Surg 1999;5(03):209-210

31 Boyer TD, Haskal ZJAmerican Association for the Study of Liver Diseases. The role of transjugular intrahepatic portosystemic shunt in the management of portal hypertension. Hepatology 2005;41(02):386-400

32 Boyer TD, Haskal ZJAmerican Association for the Study of Liver Diseases. The role of transjugular intrahepatic portosystemic shunt (TIPS) in the management of portal hypertension: update 2009. Hepatology 2010;51(01):306

33 Qi X, Han G, Yin Z, et al. Transjugular intrahepatic portosystemic shunt for portal cavernoma with symptomatic portal hypertension in non-cirrhotic patients. Dig Dis Sci 2012;57(04):1072-1082

34 Sharma A, Keshava SN, Eapen A, Elias E, Eapen CE. An update on the management of Budd-Chiari syndrome. Dig Dis Sci 2021;66 (06): $1780-1790$

35 Ahmed M, Keshava SN. Interventions for portal hypertension: trans jugular intrahepatic portosystemic shunts (TIPS). In: Mukund A, ed. Basics of Hepatobiliary Interventions. 1st ed. Singapore: Springer; 2021:187-200 